\title{
Paleolimnology and the restoration of aquatic systems
}

\author{
Peter Gell ${ }^{1}$, H. Bennion ${ }^{2}$ and R. Battarbee ${ }^{2}$
}

'Science and Engineering, University of Ballarat, Australia; p.gell@ballarat.edu.au 2Environmental Change Research Centre, University College London, UK

Recent developments in environmental management include the rehabilitation, or even restoration, of aquatic ecosystems. This is enshrined in regional management strategies and international legislation, such as the European Water Framework Directive (WFD) that intends to return all waterbodies to "good ecological status" by 2015 (EU, 2000). At all scales, the management of these systems is dependent on the identification of a target condition for restoration. However, agreeing what the target condition should be is not easy. The different stresses caused by human activity need to be recognized and the target needs to accommodate the role of natural processes as well as the expected response from reduced human influence. Climate variability, in particular, has impacts on the hydrological balance of wetlands and lakes, some of which are sensitive to pressure, whereas others are resilient. The determination of natural ecological conditions frequently relies on instrumental data or short-term process studies. Given the range of natural variability and possible responses to human impacts, both approaches lack the timescale required to identify pre-impact (or reference) conditions, or to document the changes that have since taken place. In many aquatic systems, however, paleolimnological methods can provide the missing information.

Paleolimnology has sought to identify long-term changes in the condition of lakes and wetlands, and has correlated changing conditions to environmental and climate drivers at a range of temporal scales, often enabling the historic range of variability to be determined (e.g., Haberle et al., 2006). Paleolimnology can be employed to identify the initial point of change when the condition of a lake first departed from natural patterns of variability, and so can reveal the responsiveness of the waterbody to human impacts. Tracking environmental changes in sediment records can reveal pre-impact conditions, trajectories of change, and identify any signs of recovery. In this context, paleolimnological studies have made a major contribution to the implementation of legislation, such as the WFD (Bennion and Battarbee, 2007), especially with respect to the major problems of acidification and eutrophication.
Acidification of lake surface waters has been a matter of environmental concern for several decades. In the 1980s, paleolimnological methods helped establish that "acid rain" was the principal cause of acidification (e.g., Battarbee, 1990). Today, following major reductions in the emissions of sulphur and nitrogen gases, lakes and streams in acidified regions of Europe and North America are beginning to recover. The extent of the recovery so far, however, is limited, especially when judged by the difference between the current status of these ecosystems and the pre-acidification reference state revealed by paleolimnological analysis. Recovery is expected to continue but other influences on the ecology of recovering ecosystems, such as climate change, may cause entirely new ecosystem conditions to develop in the future. In this eventuality, the past reference conditions defined by using paleolimnology may become an impossible target for restoration but will nevertheless remain as a benchmark that will help assess future deviation from the natural background or reference condition.

Eutrophication is recognized as a major influence on the ecological condition of lakes and wetlands. While there have been considerable nutrient reductions in surface waters in the past few decades, the long history of human impact on the landscape makes it difficult to find minimally disturbed reference sites for many ecosystem types. In such cases, paleolimnology provides arguably the only technique for establishing a reference condition. Hence, to assist with implementation of the WFD in numerous European lakes, biological remains in sediment records combined with transfer functions have been employed to define ecological and chemical reference conditions, and assess deviation from the reference state (Bennion and Battarbee, 2007). Battarbee et al. (2007), in an analysis of paleodata from 100 lakes, found few cases of eutrophication in Europe before $\sim 1900$, showing that conditions pre $\sim 1850$ represent a reference for efforts to restore surface waters to "good status" (see Fig. 1). Nevertheless, for some lakes with long histories of agriculture in their catchments, paleo-studies indicate that eutrophication can date back to the Bronze Age (e.g., Bradshaw et al., 2005), thereby suggesting that 1850 is an unsuitable baseline in such cases.

There are an increasing suite of instances where paleolimnological approaches have provided the critical temporal context to inform the challenging decisions that emerge for the management of "stressed" waterbodies worldwide. While restoring the past states identified by these techniques may be beyond the management capacity of our modified catchments, they plainly reveal the

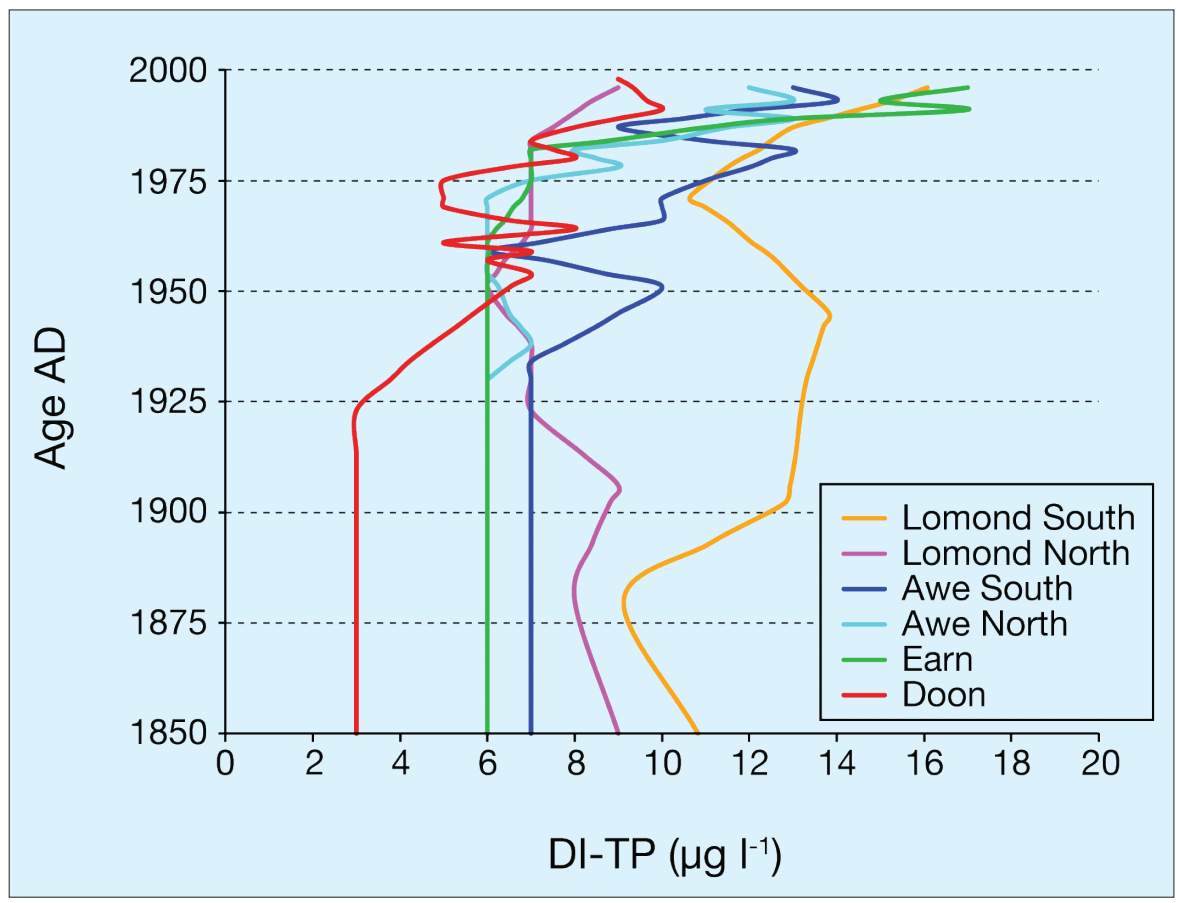

Figure 1: Diatom-inferred total phosphorus (DI-TP) concentrations $\left(\mu \mathrm{g} \mathrm{L}^{-1}\right)$ for five Scottish loch basins, showing enrichment after 1850 AD (modified from Bennion et al., 2004) 
dimensions of the impact industrialized society has had on the natural world, aid the identification of the timing and drivers of change, and establish a benchmark against which managers can evaluate the degree to which their restoration efforts are successful.

\section{References}

Battarbee, R.W. 1990: The causes of lake acidification, with special reference to the role of acid deposition, Philosophical Transactions of the Royal Society, London B, 327: 339-347.

Bennion, H. and Battarbee R., 2007: The European Union Water Framework Directive: opportunities for palaeolimnology, Journal of Paleolimnology, 38: 285-295.

Bennion, H., Fluin, J. and Simpson, G.L. 2004: Assessing eutrophication and reference conditions for $S$ cottish freshwater lochs using subfossil diatoms, Journal of Applied Ecology, 41: 124-138.
Bradshaw, E.G., Rasmussen, P. and Odgaard, B.V., 2005: Mid- to lateHolocene change and lake development at Dallund $\emptyset_{\text {, Denmark }}$ synthesis of multiproxy data, linking land and lake, The Holocene, 15: 1152-1162.

Haberle, S.G., Tibby, J.C., Dimitriadis, S. and Heijnis, H., 2006: The impact of European occupation on terrestrial and aquatic ecosystem dynamics in an Australian tropical rain forest, Journal of Ecology, 94: $987-1002$

For full references please consult:

www.pages-igbp.org/products/newsletters/ref2009_3.html

\section{The $11^{\text {th }}$ International Paleolimnology Symposium}

\section{Guadalajara, Mexico, 15 - 18 December 2009}

We deeply regretted that the $11^{\text {th }}$ International Paleolimnology Symposium, originally planned for June 2009, had to be postponed due to the influenza outbreak in Mexico.

The symposium will now be held in Guadalajara from the 15-18 December 2009. We would like to encourage the paleolimnology community to make a special effort to support the IPA symposium this year by coming to Mexico! On-site registration is available.

Sessions include:

- General paleolimnology

- Age-depth modeling

- Stable isotopes - advances in techniques and interpretation

- Organic geochemical paleoclimate proxies in lakes and bogs

- Lake-sediment archives of trace-metals and organic contaminants

- Paleolimnology of shallow lakes

- Varved and laminated lacustrine sediments

- Paleolimnological studies of arid regions of Eurasia

- Mountain lakes - exploring the sedimentary record of environmental change at higher altitudes

- Paleolimnology of high-latitude regions of the Northern Hemisphere

- Late Quaternary paleo-climate and -environmental records in lakes from the S. Hemisphere

- Human-environment interactions in the Americas

- Rapid events and human answers as reconstructed from lacustrine archives

- Quantifying the lake record of "paleo-precipitation" during the last 2 ka

- Floodplain lake sediments as archives for environmental history

- Paleolimnological applications in estuarine and coastal environments

We would also like to draw your attention to the "IPA Lifetime Achievement Award", which will be presented for the first time at this meeting, to Daniel Livingstone, Herbert Wright, Walter Dean and Frank Oldfield.

For more information see http://www.geofisica.unam.mx/paleolimnologia
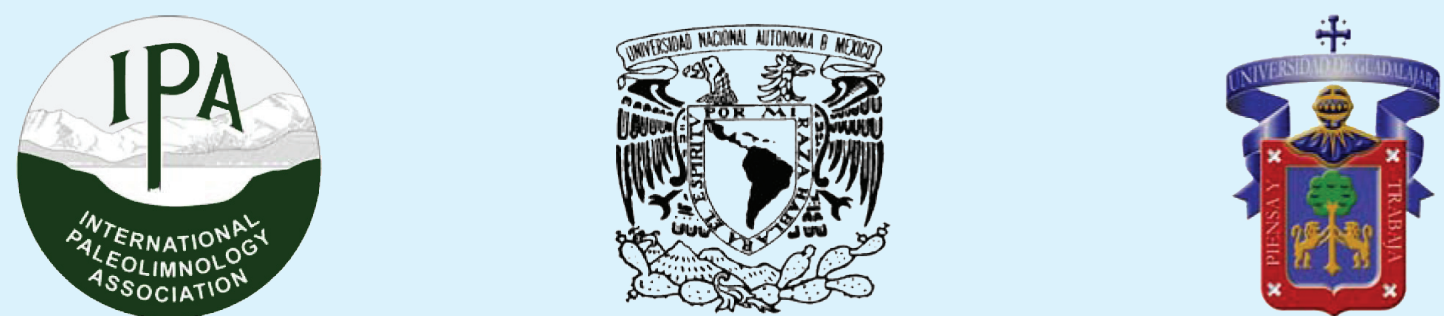